\title{
Mourning and Melancholia, Sigmund Freud (1917) - The 100-year anniversary of the publication of this landmark essay about depression
}

\author{
Luto e Melancolia, Sigmund Freud (1917) - O centenário \\ da publicação desta referência sobre depressão
}

Antonio E. Nardi

Sigmund Freud's "Mourning and Melancholia"1 ("Trauer und Melancholie") was published one-hundred years ago, but this seminal essay continues to guide clinical psychiatrists in the distinction between the diagnosis of clinical depression and of prolonged grief. Notably this distinction is vital in preventing the over-prescription of antidepressants, or even general medical assistance, to patients suffering from grief. In this text, Freud argues that grief and melancholia have characteristics that overlap with those of depression but that they might be understood as different responses to loss. What makes Freud's text unique is its descriptiveness of these two states, which elevates his text from a scientific one to having also an artistic element.

It is evident that there are challenges in diagnosing depression or grief. The Diagnostic and Statistical Manual of Mental Disorders, $5^{\text {th }}$ Edition (DSM-5) task force had proposed a new diagnosis to describe persistent and severe grief reactions. In its final version, the DSM-5 relegated it to the Appendix on the basis that there was insufficient evidence to have it recognized as a separate diagnosis.

Freud's text overcomes this challenge and in drawing out the distinctions between grief and depression through description, thus separating a natural human response from a mental disorder. When in mourning, a person deals with the loss of a specific love object, and this process in Freud's point of view takes place in the conscious mind. The key distinction is that this is considered a healthy and natural process, while melancholia is considered pathological with many symptoms and disabilities in everyday life. Some symptoms might be common to both cases, and these might include inhibition and disinterest in the external world. Grief is not pathological and the majority of mental health professionals agree that it does not require medical interference. On the other hand, depression is a serious mental disorder with a plethora of symptoms and a high risk of suicide. There is no doubt that prolonged grieving exists and can be very psychological painful, but some argue that classifying it as a mental disorder is unwarranted and may inadvertently encourage unnecessary treatment.

It is important to note, however, that "uncomplicated" grief may develop into an acute depressive state. People have a natural healing process after a loss, but sometimes this process is blocked or derailed. The resulting condition includes acute grief symptoms, such as yearning and longing, and other intense emotions and complicating problems, such as rumination or avoidance or ineffective emotion regulation. Some psychiatrists argue that it should not be classified as a separate entity, that complicated grief is actually a subset

1 Federal University of Rio de Janeiro (UFRJ). National Academy of Medicine, Brazil.

Received on

$11 / 28 / 2016$

Approved on

12/13/2016
Address for correspondence: Antonio E. Nard

E-mail: antonioenardi@gmail.com 
of another mental disorder such as depression itself, adjustment disorder, or posttraumatic stress.

Many symptoms of complicated grief overlap with what has been called uncomplicated grief. That automatically opens the door for more disagreement over diagnosis, as the following questions need to be addressed: At what point does uncomplicated grief cross into the realm of complicated grief? Does the complicated grief need medical care? Does it need medication? What are the risks for depression? Only a profound comprehension of human feelings from the arts and clinical psychopathology from the classical texts can guide us through such important clinical moments. Let's reread Freud's Mourning and Melancholia, and celebrate this monumental publication.

\section{REFERENCE}

1. Freud S. (1917). Mourning and Melancholia. The Standard Edition of the Complete Psychological Works of Sigmund Freud, Volume XIV (1914-1916): On the History of the PsychoAnalytic Movement, Papers on Metapsychology and Other Works, p. 237-58. 